\title{
Discharge Chamber Plasma Structure of a 30-cm NSTAR-type Ion Engine
}

\author{
Daniel A. Herman ${ }^{\dagger}$ and Alec D. Gallimore \\ Plasmadynamics and Electric Propulsion Laboratory \\ University of Michigan, Ann Arbor, MI 48109 USA
}

\begin{abstract}
Single Langmuir probe measurements are presented for a two-dimensional array of locations in the near Discharge Cathode Assembly (DCA) region of a 30-cm diameter ring-cusp ion thruster over a range of thruster operating conditions encompassing the high-power half of the NASA throttling table. All data were analyzed assuming an electron population consisting of Maxwellian electrons only yielding repeatable results that agree with previous double probe measurements. Unsuccessful attempts were made to analyze the on-axis Langmuir probe data assuming both Maxwellian and primary electrons, yielding inaccurate results that were hyper sensitive to the analysis input parameters. Discharge plasma data taken with beam extraction exhibit a broadening of the higher electron temperature plume boundary compared to similar discharge conditions without beam extraction. The opposite effect is evident with the electron/ion number density as the data without beam extraction appears to be more collimated than the corresponding data with beam extraction. Shorting the discharge cathode keeper to common had no noticeable effect on the discharge plasma.
\end{abstract}

$\mathrm{A}_{\mathrm{p}} \quad=$ probe surface area, $\mathrm{m}^{2}$

$\mathrm{A}_{\mathrm{s}} \quad=$ ion collection area, $\mathrm{m}^{2}$

$\mathrm{B}_{1}=$ primary electron current intercept, $\mathrm{A}$

$\mathrm{B}_{2}=$ primary electron current slope, $\mathrm{A} / \mathrm{V}$

$\mathrm{B}_{3}=\mathrm{I}_{\mathrm{e}, \mathrm{sat}} \exp \left(-\phi_{\mathrm{p}} / \mathrm{T}_{\mathrm{eV}}\right), \mathrm{A}$

$\mathrm{B}_{4}=1 / \mathrm{T}_{\mathrm{ev}}, \mathrm{A}$

$\mathrm{e}, \mathrm{q}=$ electron charge, $1.6 \times 10^{-19} \mathrm{C}$

$\mathrm{I}=$ probe collected current, $\mathrm{mA}$

$\mathrm{I}_{\mathrm{e}, \text { sat }}=$ electron saturation current, $\mathrm{A}$

$\mathrm{I}_{\text {ion, sat }}=$ ion saturation current, $\mathrm{A}$

$\mathrm{i}_{\mathrm{p}}=$ primary electron current at $\phi_{\mathrm{p}}, \mathrm{mA}$

$\mathrm{A}_{\mathrm{por} \mathrm{s}}=$ probe or collection area respectively, $\mathrm{m}^{2}$

$\mathrm{J}_{\mathrm{a}}=$ acceleration grid current, $\mathrm{mA}$

$\mathrm{J}_{\mathrm{b}}=$ beam current, $\mathrm{A}$

$\mathrm{J}_{\mathrm{dc}}=$ discharge current, $\mathrm{A}$

$\mathrm{J}_{\mathrm{nk}}=$ neutralizer keeper current, $\mathrm{A}$

$\mathrm{k}=$ Boltzmann's constant, $1.38 \times 10^{-23} \mathrm{~J} / \mathrm{K}$

$\mathrm{M}_{\mathrm{Xe}}=$ atomic mass of xenon, $\mathrm{kg}$

$\mathrm{m}_{\mathrm{e}} \quad=$ electron mass, $9.1094 \times 1031 \mathrm{~kg}$

\section{Nomenclature}

$\begin{array}{ll}\mathrm{n}_{\mathrm{e}, \mathrm{m}} & =\text { Maxwellian electron number density, } \mathrm{cm}^{-3} \\ \mathrm{n}_{\mathrm{e}, \mathrm{p}} & =\text { primary electron number density, } \mathrm{cm}^{-3} \\ \mathrm{n}_{\mathrm{i}} & =\text { ion number density, } \mathrm{cm}^{-3} \\ \mathrm{P}_{\mathrm{b}} & =\text { base pressure (air), Torr } \\ \mathrm{P}_{\mathrm{c}} & =\text { corrected pressure (on xenon), Torr } \\ \mathrm{P}_{\mathrm{i}} & =\text { indicated pressure (with xenon flow), Torr } \\ \mathrm{r} & =\text { probe electrode radius, } \mathrm{m} \\ \mathrm{T}_{\mathrm{eV}} & =\text { Maxwellian electron temperature, } \mathrm{eV} \\ \mathrm{V}_{\mathrm{a}} & =\text { acceleration grid voltage, } \mathrm{V} \\ \mathrm{V}_{\text {bias }} & =\text { probe bias w.r.t. disch. cath. common, } \mathrm{V} \\ \mathrm{V}_{\mathrm{ck}-\mathrm{cc}} & =\text { keeper to cathode common voltage, } \mathrm{V} \\ \mathrm{V}_{\mathrm{d}} & =\text { discharge voltage, } \mathrm{V} \\ \mathrm{V}_{\mathrm{g}} & =\text { neutralizer to ground coupling voltage, } \mathrm{V} \\ \mathrm{V}_{\mathrm{nk}} & =\text { neutralizer keeper voltage, } \mathrm{V} \\ \mathrm{V}_{\mathrm{s}} & =\text { screen grid voltage, } \mathrm{V} \\ \lambda_{\mathrm{b}} & =\text { debye length, cm or mm } \\ \phi_{\mathrm{p}} & =\text { plasma potential, } \mathrm{V} \\ ?_{\mathrm{p}} & =\text { primary electron energy, eV } \\ \delta & =\text { sheath thickness, cm }\end{array}$

\footnotetext{
${ }^{*}$ Color copies available at http://www.engin.umich.edu/dept/aero/spacelab/publications/conf_pub.html

† Graduate Student, Aerospace Engineering, hermo@engin.umich.edu, 1919 Green Rd Room B107, Member AIAA.

${ }^{\ddagger}$ Professor and Laboratory Director, Aerospace Engineering, Alec.gallimore@ umich.edu, Associate Fellow AIAA.
} 


\section{Introduction}

I on thrusters are high-efficiency, high-specific impulse $\left(\mathrm{I}_{\mathrm{sp}}\right)$ propulsion systems that are being proposed as the primary propulsion source for a variety of missions. In some cases ion thruster technology has enabled new missions that had not been feasible using liquid propellant rocket technology. NASA's Dawn mission, propelled by three 30-cm ion thrusters, will study two minor planets, Ceres and Vesta, which reside in the vast asteroid belt between Mars and Jupiter. ${ }^{\S}$ The NASA Solar Electric Propulsion Technology Applications Readiness (NSTAR) 30$\mathrm{cm}$ ion thruster was the first ion engine to be used for primary spacecraft propulsion, validating ion thruster technology, and demonstrating operation for over three times its intended lifetime. ${ }^{* *}$ Nevertheless, efforts to increase engine lifetime continue.

A potential failure mechanism for an ion engine is erosion of the discharge cathode. ${ }^{1}$ Investigation of the discharge cathode erosion led to evidence that direct ion impingement was the cause. A cathode keeper was added as an engineering solution to mitigate cathode erosion on NSTAR. ${ }^{2}$ Adding the keeper reduced the cathode erosion rate to acceptable levels and until recently, was thought to have solved the Discharge Cathode Assembly (DCA) erosion issue. An Extended Life Test (ELT) of the NSTAR Deep Space One (DS1) flight spare thruster, conducted at the Jet Propulsion Laboratory (JPL), revealed extensive keeper erosion that has yet to be fully explained. ${ }^{3-6}$ Although the engine continued to operate until it was voluntarily shut down after 30,352 hours of operation (over $235 \mathrm{~kg}$ of xenon processed $)^{6}$, there exists a clear need to understand the cause of DCA erosion, how engine operating conditions affect DCA erosion, and how to reduce DCA erosion thereby extending engine lifetime. A better understanding of DCA erosion mechanisms may be even more important for the next-generation of ion engines associated with NASA's Project Prometheus that require lifetimes ranging from 44,000 to 88,000 hours. ${ }^{7,8}$

Laser Induced Fluorescence (LIF) measurements by Williams have suggested the existence of a potential hill downstream of the DCA as a possible cause of DCA erosion. ${ }^{9-11}$ In this scenario, the potential hill is responsible for accelerating a portion of the ions away from the hill towards the DCA. Mapping the internal plasma structure of the 30-cm ion engine downstream of the DCA is essential to understanding the cause of DCA erosion. These plasma parameter measurements will add to the knowledge of discharge plasma operation, discharge cathode erosion, and could potentially validate or rule out the potential hill theory. The purpose of this experiment is to take high-spatial resolution discharge plasma measurements in the near DCA region of the 30-cm ion engine.

\section{FMT2 30-cm Ion Thruster}

\section{A. Background}

The Functional Model Thruster (FMT) preceded the NSTAR Engineering Model Thruster (EMT) and the NSTAR Flight Thruster. The principal difference in the construction of the FMT from the EMT is the anode material; the FMT anode is aluminum while the EMT anode is spun aluminum and titanium. The second of two FMTs, FMT2, was modified at the NASA Glenn Research Center (GRC) by Williams to allow optical access to the discharge chamber for LIF measurements. ${ }^{9}$ Six slots were cut into FMT2: three slots in the anode wall and three slots in the plasma shield. Photographs of the FMT2 ion engine and the LIF modifications can be seen in Figure 1.

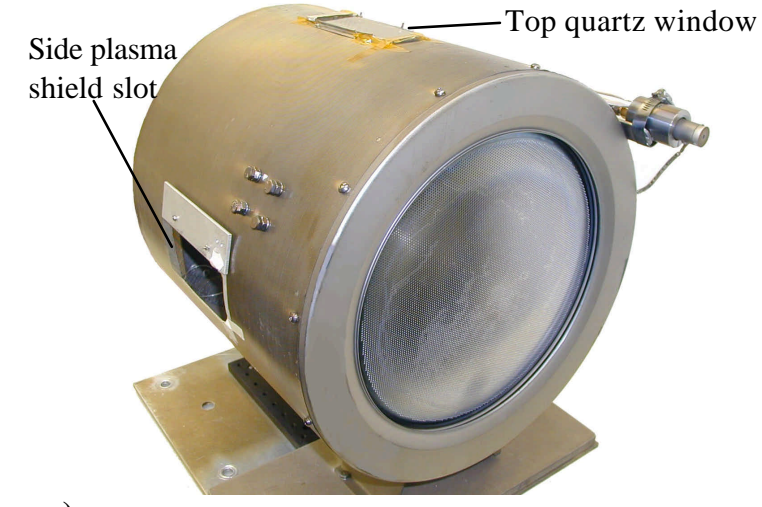

a)

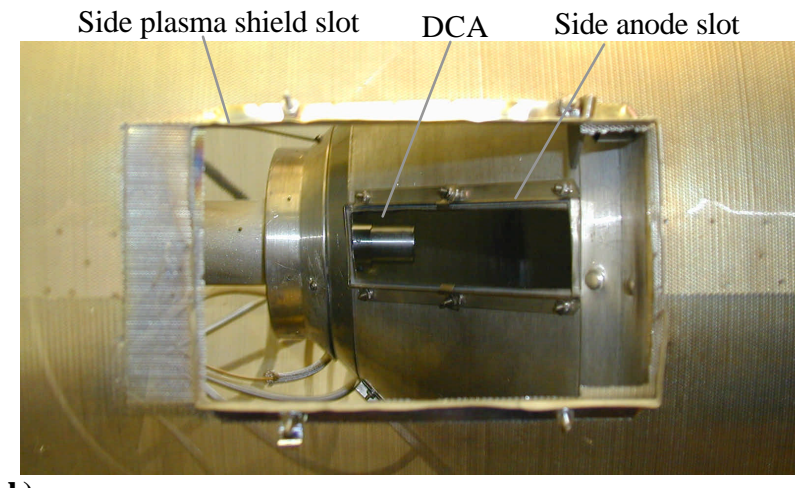

b)

Figure 1. The FMT2 ion engine illustrating the locations of the top and side quarts window mount a), as well as a close-up view of the FMT2 side LIF slots and quartz window mounts with quartz removed b).

$\S$ http://solarsystem.nasa.gov/missions/astmissns/ast-dawn.html

** http://nmp.jpl.nasa.gov/ds1/gen/mission.html 
The magnetic field, DCA, and geometry of the discharge chamber are identical to those of EMT1. ${ }^{9}$ For a more complete comparison between FMT2 and EMT1 see Reference 9. The FMT2 thruster has been operated over the entire NSTAR power throttling range at GRC and at the Plasmadynamics and Electric Propulsion Laboratory (PEPL) illustrating comparable performance to the EMTs and flight thrusters. Williams has shown that these modifications have not altered the discharge chamber magnetic field, the ion production efficiency, or the overall thruster performance. ${ }^{9}$

\section{B. Discharge Plasma Containment Mechanism}

The side anode quartz window is replaced by a discharge plasma containment mechanism allowing electrostatic probe access inside the anode. The design, shown in Figure 2, consists of a series of overlapping 38-guage slotted stainless steel sheets.

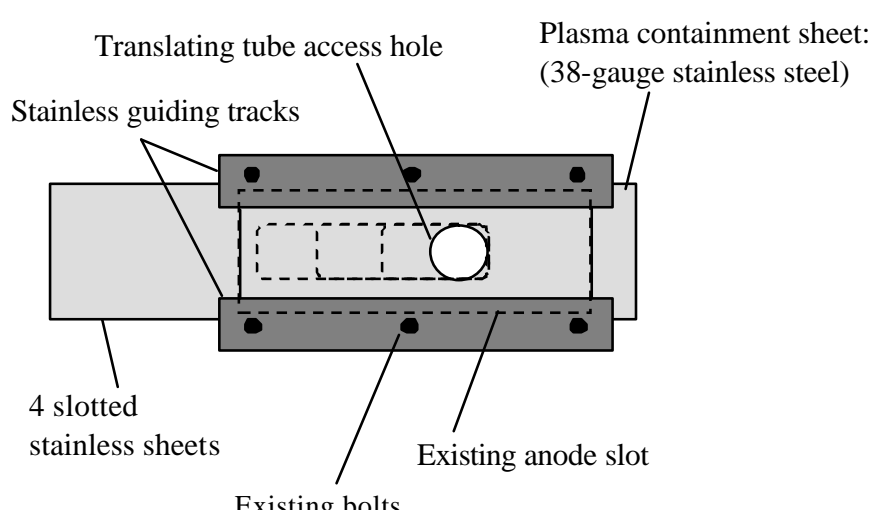

a)

Existing bolts

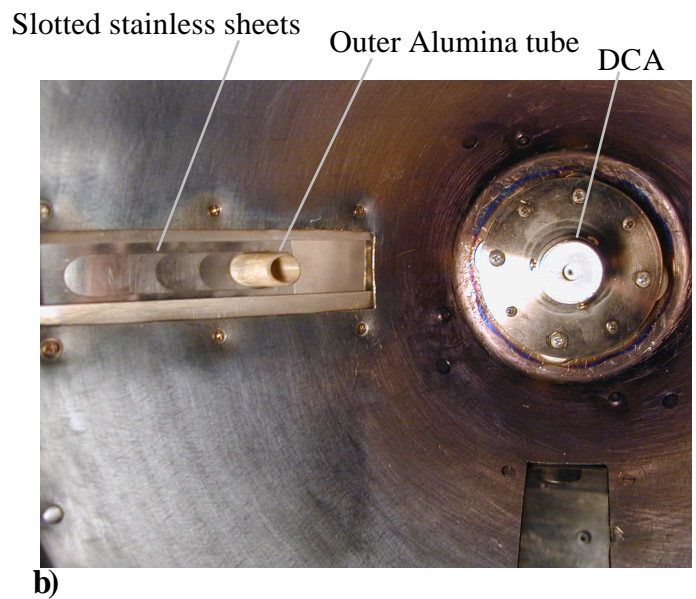

Figure 2. Schematic of the discharge plasma containment hardware covering the anode side slot shown in a), along with a photograph taken inside the FMT2 discharge chamber prior to engine testing showing the interior of the discharge plasma containment mechanism in b).

Repeatable axial movement of the probe is permissible. Discharge plasma containment is maintained and visually monitored during thruster operation via an adjacent vacuum-rated camera. Gap formation, while extracting a beam, leads to a surge of discharge plasma towards the hole as the high-voltage plasma escapes to ground. Repeated recycles of the engine ensue. The vacuum-rated camera allows confirmation that no gap formation has occurred throughout the test and that any engine recycles are not a result of gap formation.

The ability to retract and extend the translating alumina tube at various axial locations minimizes protrusion of material into the discharge chamber. The alumina tube extends approximately $1 \mathrm{~cm}$ inside of the discharge chamber wall at all axial locations. The alumina tube is mounted onto a New England Affiliated Technologies (NEAT) RMS-800 single axis ball screw table controlled via computer. The table has a lead screw accuracy of $80 \mu \mathrm{m}$ and a range of motion of $20 \mathrm{~cm}$. For more information on the discharge plasma containment mechanism shown in Figure 3 see Reference 12.

To minimize the likelihood of probe contamination and perturbing the discharge plasma, the probe is recessed in the low-density interior of the alumina tube when not in use. A rectangular aluminum plate covers the side plasma shield slot eliminating the Ine of sight of background particles (i.e., electrons) to the high potential anode.

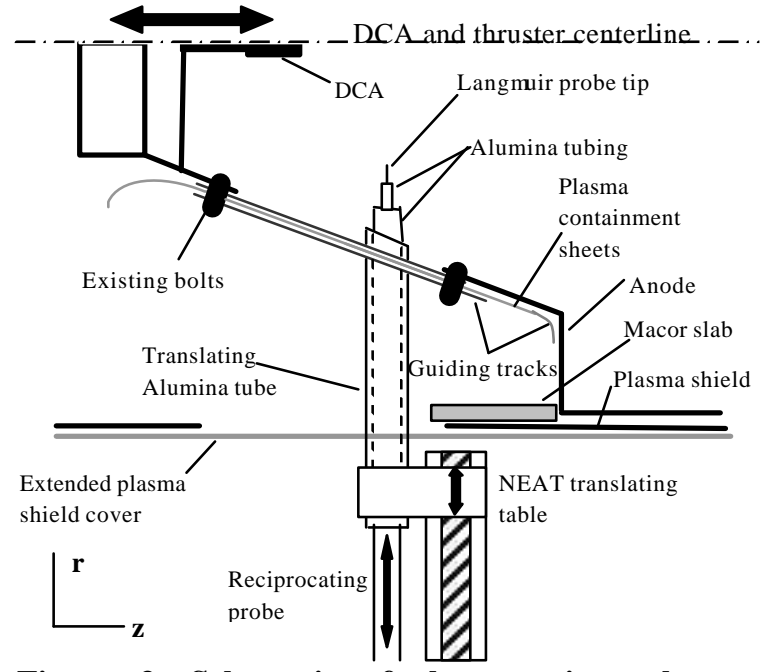

Figure 3. Schematic of the experimental setup focusing on the discharge plasma containment and thruster orientation. 


\section{Apparatus and Procedure}

\section{A. Vacuum Facility}

All experiments are performed in the $6 \mathrm{~m}$ by $9 \mathrm{~m}$ Large Vacuum Test Facility (LVTF) at PEPL. Four of the seven CVI Model TM-1200 Re-Entrant Cryopumps are used for these experiments, which provide a combined pumping speed of 140,000 1/s on xenon with a base pressure of $\sim 3 \times 10^{-7}$ Torr. Chamber pressure is recorded using a hot-cathode ionization gauge mounted directly on the chamber wall. A complete neutral pressure map of the LVTF has shown that the wall-mounted ion gauge pressure is representative of the chamber background pressure near the thruster in this facility. ${ }^{13}$ Pressure measurements are corrected for xenon using the known base pressure on air and a correction factor of 2.87 for xenon according to, ${ }^{13-15}$

$$
P_{c}=\frac{P_{i}-P_{b}}{2.87}+P_{b} .
$$

A dedicated propellant feed system, consisting of three Edwards mass flow controllers, provided by NASA GRC, controls the xenon flow rate to the thruster. The flow rates are periodically calibrated using a known volume technique.

A $2 \mathrm{~m}$ by $2.5 \mathrm{~m}$ louvered graphite panel beam dump is positioned approximately $4 \mathrm{~m}$ downstream of the FMT2 thruster to reduce back sputtering. The thruster is operated at PEPL using a modified Station-Keeping Ion Thruster Package (SKIT-Pac) power processing and control rack provided by NASA GRC. Unless specified otherwise, the discharge cathode keeper is electrically tied to the anode by a $10 \mathrm{k}$ ? resistor throughout testing.

\section{B. High-speed Axial Reciprocating Probe (HARP)}

A linear motor assembly provides highly accurate direct linear motion of the probe with minimal residence times in the discharge cathode plume. The HARP system is a three-phase brushless dc servo motor consisting of a linear "U"-shaped magnet track and a "T"-shaped coil moving on a set of linear tracks. The linear encoder provides positioning resolution to $5 \mu \mathrm{m} .{ }^{16}$ A Pacific Scientific SC950 digital, brushless servo drive controls the motor. The entire table is enclosed in a stainless steel shroud with a graphite outer skin. The residence time of the probe downstream of the DCA, inside the high-density discharge cathode plume, is typically 100 milliseconds. The short residence times minimize the discharge plasma perturbation during probe insertion, which is monitored by the discharge current perturbation during probe insertion. The maximum perturbation recorded during probe insertion is $5-10 \%$ of the discharge current nominal value. Additional information on the HARP system can be found in References 16 and 17.

\section{Axial Movement}

The FMT2 is mounted on an ATS62150 Aerotech single-axis translational stage. The Aerotech axis controls the engine axial location with respect to the probe to an absolute position accuracy of $0.15 \mathrm{~mm}$. The axial step size is set at $1.5 \mathrm{~mm}$ to give adequate resolution of the near DCA plasma structure.

The electrostatic probe is radially positioned inside the discharge chamber using the HARP. Both the HARP system and the Aerotech table are mounted on a common structure whose foundation is the vacuum facility wall. This setup minimizes alignment shifts occurring during evacuation of the vacuum facility. When actuated, the probe extends to the thruster centerline then returns to the starting location recessed inside the translating alumina tube. The RMS-800 NEAT table retracts and extends the translating alumina tube as the axial location changes. The full 2-D data collection domain is illustrated in Figure 4. 

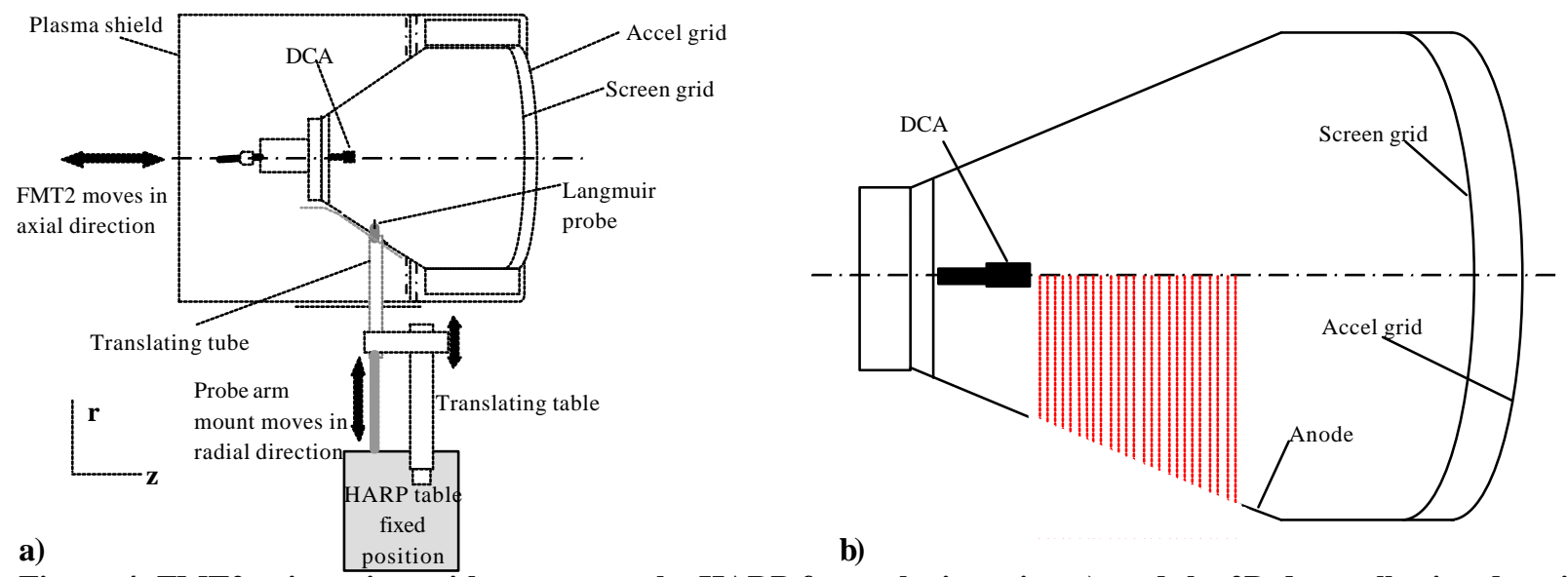

Figure 4. FMT2 orientation with respect to the HARP for probe insertion a), and the 2D data collection domain starting at an axial location of $1.5 \mathrm{~mm}$ from the DCA and extending in $1.5 \mathrm{~mm}$ increments b).

\section{FMT2 Thruster Operation}

For this near DCA investigation, the primary thruster operating parameters of interest are the discharge current and voltage, the screen voltage, and the beam current. For each operating condition, without beam extraction, the discharge current is set to the desired value corresponding to the discharge current in the NASA Throttling table (TH Level). The main anode flow rate and discharge cathode flow rate are adjusted to match the discharge voltage of the desired NASA TH Level. The discharge only operating conditions, i.e. without beam extraction, of the FMT2 are referred to as Discharge Levels (DL).

The procedure for operating the FMT-2 with beam extraction is to throttle up the discharge current and screen voltage to match the desired NASA TH Level discharge current. The main and discharge flow rates are adjusted until both the discharge cathode voltage and beam current match those recorded in the NASA throttling table. The data taken with beam extraction are referred to as Thruster Operating Conditions (TOC Levels). Table 1 lists the discharge parameters for the operating conditions investigated. A complete listing of the thruster telemetry can be found in the Appendix.

The typical data collection time was one hour for each operating condition. In order to maintain discharge voltage and beam current, the cathode and main flow rates were adjusted during data collection. The maximum and minimum flow rates during data collection are recorded.

Table 1. FMT2 discharge operation parameters for Thruster Operating Conditions with beam extraction (TOC) and Discharge Levels without beam extraction (DL) roughly corresponding to the same discharge current and voltage as NASA Throttling Levels (TH).

\begin{tabular}{|c|c|c|c|c|c|c|c|c|}
\hline \multirow{2}{*}{ Level } & \multicolumn{2}{|c|}{} & \multicolumn{2}{c|}{$\begin{array}{c}\text { Main Flowrate } \\
\text { [ }\end{array}$} & \multicolumn{2}{c|}{$\begin{array}{c}\text { Disch Cath } \\
\text { Flowrate }[\mathrm{sccm}]\end{array}$} & $\begin{array}{c}\text { Corrected } \\
\text { Pressure }\end{array}$ \\
\cline { 2 - 9 } & $\max$ & & $\min$ & $\max$ & $\min$ & $\max$ & {$[$ Torr] } \\
\hline \hline DL 8 & 25.05 & 25.19 & 8.24 & 15.3 & 16.1 & 3.77 & 3.91 & $1.9 \mathrm{E}-06$ \\
\hline TOC 8a & 25.10 & 25.14 & 8.24 & 15.8 & 16.3 & 3.61 & 4.01 & $2.3 \mathrm{E}-06$ \\
\hline TOC 8 & 25.05 & 25.15 & 8.24 & 15.5 & 15.5 & 4.84 & 4.90 & $2.3 \mathrm{E}-06$ \\
\hline $\begin{array}{c}\text { TOC 8 CK } \\
\text { C s short }\end{array}$ & 25.05 & 25.15 & 8.24 & 15.5 & 15.5 & 4.90 & 4.95 & $2.4 \mathrm{E}-06$ \\
\hline DL 12 & 25.40 & 25.50 & 10.87 & 15.5 & 15.9 & 2.90 & 2.97 & $1.8 \mathrm{E}-06$ \\
\hline TOC 12 & 25.35 & 25.45 & 10.87 & 21.0 & 21.2 & 3.21 & 3.40 & $2.7 \mathrm{E}-06$ \\
\hline DL 15 & 25.30 & 25.50 & 13.13 & 15.1 & 15.1 & 2.73 & 2.81 & $1.8 \mathrm{E}-06$ \\
\hline TOC 15 & 25.05 & 25.15 & 13.13 & 24.5 & 24.5 & 3.06 & 3.06 & $2.9 \mathrm{E}-06$ \\
\hline
\end{tabular}




\section{Electrostatic Probe}

\section{A. Langmuir Probe Type}

Electrostatic double probe measurements were previously made using a double probe inside the FMT2 engine. ${ }^{18}$ While the double probe has the advantage that it floats as a whole, thus minimizing discharge plasma perturbation, the maximum ion current from one electrode limits the electron current measured by the other. Thus only the high energy electrons are sampled. The double probe measurement is further hindered in this application by inadequate resolution needed to map the near DCA plasma structure. The magnetic field of the ion engine effectively confines the discharge cathode emitted electrons to a narrow plume immediately downstream of the discharge cathode. A requirement of the applicability of the double probe is a large gap between electrodes such that the sheaths of the electrodes do not overlap. This constraint reduces the spatial resolution of the double probe, most noticeably near the discharge cathode exit plane, likely leading to an underprediction of number density near cathode centerline.

Considering the aforementioned points, a single Langmuir probe was designed to acquire discharge plasma measurements for similar operating conditions as the double probe. The single Langmuir probe should yield slightly higher number density measurements at the discharge cathode exit plane on centerline as a result of its alignment with the cathode plume. Furthermore, the single Langmuir probe has the potential to allow extraction of the primary ${ }^{\dagger \dagger}$ electron number density and energy provided a reliable analysis method can be determined.

\section{B. Single Probe Hardware}

While probes always perturb their surroundings, the extent of the perturbation is minimized by making the probe as small as possible. This desire also bodes well with the need to maintain adequate spatial resolution and decreases the possibility of probe melting. To minimize the plasma losses to the probe, which would unduly perturb the discharge plasma, the probe size is minimized while maintaining measurable ion saturation current based on predicted plasma parameters.

The electrode of the single Langmuir probe typically is sized such that, for the expected electron temperature ( 2 $11 \mathrm{eV})^{19,20}$ and previously measured number densities $\left(10^{10}-10^{12} \mathrm{~cm}^{-3}\right),{ }^{19,21}$ the probe operates in the thin sheath regime. Inside the ion engine, the number densities are expected to have a maximum on cathode centerline and decrease by over two orders of magnitude with increasing radial distance from centerline driving an ever-increasing Debye length. The relationship of the Debye length to electron number density and temperature is illustrated in Equation 2:22,23

$$
\lambda_{D}=743 \sqrt{\frac{T_{e V}}{n_{e}}} .
$$

In the thin sheath regime, the flux of particles entering the sheath can be calculated without considering the details about the orbits of these particles in the sheath. ${ }^{24-27}$ In this case, the collection area of the electrode is approximated as the area of the electrode, which is justified for a large ratio of probe radius, $r$, to Debye length, $\lambda_{\mathrm{D}}{ }^{24,25,27}$ However, the rapid growth in the Debye length with increasing radial distance from cathode centerline dictates that at some radial location inside the anode, the thin sheath criterion may not strictly apply. The opposing electrode size requirements led to a compromise that allows the probe to operate in the thin sheath regime near cathode centerline, but not outside of the cathode plume strictly speaking. The Debye length is expected to grow to the same order of magnitude as the electrode radius near the anode, indicating operation in the transition range between thin sheath and orbital motion limited (OML). All measured number densities are corrected to account for a growing sheath.

Three similar Langmuir probes were used during the test. All probes were slight variations on the basic probe design used (Figure 5), consisting of a 0.18 -mm-diameter cylindrical tungsten electrode, with roughly $2 \mathrm{~mm}$ of exposed length. The electrode is held inside a double-bore piece of $99.8 \%$ pure alumina epoxied to one larger doublebore piece of $99.8 \%$ pure alumina. The larger alumina tube is isolated, but extends the full length of the probe inside of a grounded shield, which is itself isolated from the plasma by an outer alumina shell. The total length probe is approximately $0.5 \mathrm{~m}$. The grounded shield reduces electromagnetic interference with the probe signals.

\footnotetext{
${ }^{i \dagger}$ Primary electrons are those that have been accelerated by the full discharge cathode to bulk plasma potential and have not undergone a collision.
} 


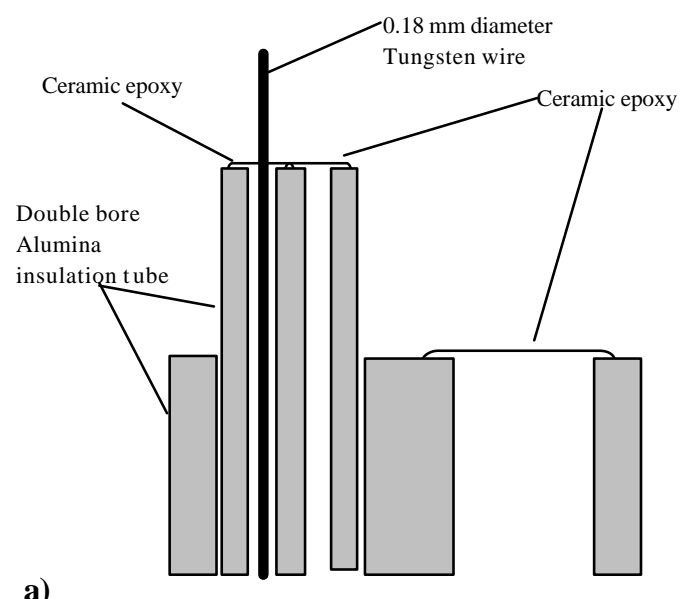

a)

Figure 5. Reduced blockage Langmuir probe tip design internal schematic shown in a), and an external schematic of emissive probe tip design shown in b).

\section{Single Langmuir Probe Electronics}

Even when drawn back in the alumina tube, the probe is exposed to the discharge plasma, which is at a potential up to $1100 \mathrm{~V}$ above ground. Significant errors in the measured current can occur due to any appreciable stray capacitance in the circuit. As such, careful attention is paid to minimizing stray capacitance in the circuit design including the use of batteries to supply the bias voltage. ${ }^{16-}$

${ }^{18}$ A potentiometer attached to the battery output sets the electrode bias voltage.

The Langmuir probe circuit, a modified version of the double probe circuit, $^{16-18}$ is built around two Analog Devices AD210 isolation amplifiers. These amplifiers are capable of handling up to 2500 volts of common mode voltage and provide an input impedance of $10^{12} \Omega$. The low-impedance output (1 $\Omega$ maximum) is connected to a Tektronix TDS 3034B digital oscilloscope that records the data and saves it to a computer once it is triggered by the

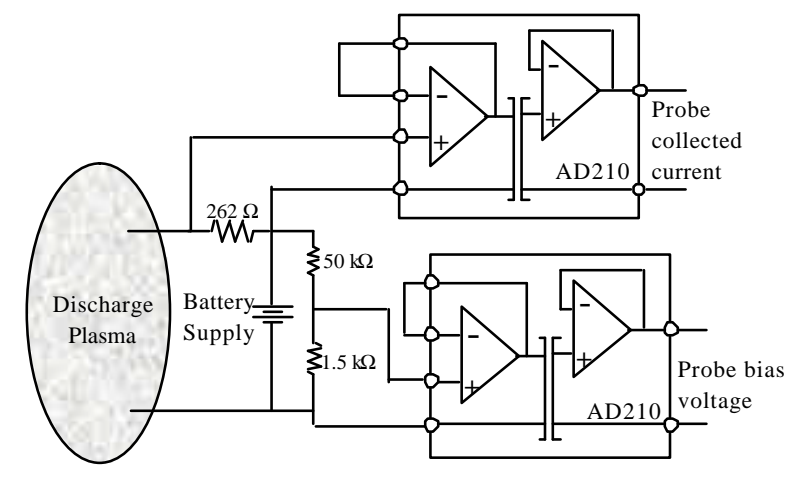

Figure 6. Single Langmuir probe circuit. HARP. Figure 6 illustrates the Langmuir probe circuit. The outputs of the isolation amplifiers are calibrated with known currents and bias voltages over their entire operating ranges.

\section{Data Acquisition}

The Aerotech translational stage and NEAT RMS-800 stage are controlled via GPIB connections through LabVIEW. A LabVIEW code steps through the full axial range of motion in $1.5 \mathrm{~mm}$ increments starting $1.5 \mathrm{~mm}$ downstream of the DCA exit plane. Electrode bias voltages, referenced to discharge cathode common, are set manually using a potentiometer and the battery supply. The probe is then swept through all spatial locations. The bias voltage, which ranges \pm 40 volts, is then manually changed and the process repeats until full I-V characteristics are recorded. Bias voltage resolution was set to $1 \mathrm{~V}$ in the electron collecting region of the current trace to decrease the data collection time to a reasonable value.

Only data taken on the "in sweep" of the probe are analyzed as "out sweep" data are more likely to be affected by probe perturbation. The discharge current perturbation induced by the probe is measured using a Hall probe, in conjunction with the Tektronix TDS 3034B oscilloscope. The maximum discharge current perturbation is approximately $5-10 \%$ of the nominal value and is undetectable when the probe is outside of the discharge cathode plume. 


\section{Data Analysis}

The scientific graphing package Igor is used to analyze the data. The data are read into Igor, which reassembles the data into individual characteristics at each spatial location in the two-dimensional grid. As the electron and ion mean free paths are much larger than the probe dimensions, a collisionless analysis is warranted. Particles are assumed to be collected without reflection or reaction inside the electrode collection area. The presence of a magnetic field has a negligible effect on the probe measurements since the analysis infers ion number density from the ion saturation current and therefore is unaffected by the reduction in electron saturation current caused by the presence of a magnetic field. However, the magnetic field can lead to electron energy distribution function (EEDF) anisotropy. Passoth $^{28}$ determined that EEDF anisotropy depends upon the ratio $\mathrm{B} / \mathrm{p}_{\mathrm{o}}$, where $\mathrm{p}_{\mathrm{o}}$ is the pressure in the containment vessel (in this case the discharge chamber). It has been shown experimentally that EEDF anisotropy is negligible for $\mathrm{B} / \mathrm{p}_{\mathrm{o}} \leq 2.5 \times 10^{6} \mathrm{G} /$ Torr. $^{29}$ In the FMT2, B has a maximum (downstream of the DCA) of on the order of $100 \mathrm{G}$ and the pressure in the discharge chamber is estimated to be $\sim 10^{-4}$ Torr. The value of $\mathrm{B} / \mathrm{p}_{\mathrm{o}}$ for the worst case is $1 \times 10^{6}$, therefore no substantial anisotropy in the EEDF is exp ected.

\section{A. All Maxwellian Electron Analysis}

The individual Langmuir probe characteristics are analyzed, over the 2-D grid, assuming a purely Maxwellian electron population. The inverse slope of the natural $\log$ of the electron current versus voltage plot gives the Maxwellian electron temperature.

The ion saturation current, the measured electron temperature, and the Bohm approximation ${ }^{22-24}$ for ion velocity readily give the ion number density by Equation 3. Assuming a quasi-neutral discharge plasma, the ion number density gives the total electron number density

$$
n_{i}=\frac{I_{s a t}}{0.61 A_{s} q} \sqrt{\frac{M_{X e}}{T_{e V}}}
$$

In Equations 3, $A_{s}$ is initially considered to be the electrode surface area. The true collection area depends upon the thickness of the sheath surrounding the probe. The electron temperature and the initial value for number density allow the Debye length to be calculated according to Equation 2. Assuming quasineutrality $\mathrm{n}_{\mathrm{e}} \approx \mathrm{n}_{\mathrm{i}}\left(\mathrm{in} \mathrm{cm}^{-3}\right)$ readily gives $\lambda_{\mathrm{D}}(\mathrm{cm})$. The sheath is then calculated according to Equation $4:^{27,32}$

$$
\delta=1.02 \lambda_{D}\left[\left(\frac{1}{2} \ln \left(\frac{m}{M_{X e}}\right)\right)^{1 / 2}-\frac{1}{\sqrt{2}}\right]^{1 / 2}\left[\left(\frac{1}{2} \ln \left(\frac{m}{M_{X e}}\right)\right)^{1 / 2}+\sqrt{2}\right]
$$

and the sheath area follows from Equation $5:^{26}$

$$
A_{s}=A_{p}\left(1+\frac{\delta}{r}\right)
$$

A new ion number density is calculated from this new collection area taking into account the departure from the thin sheath regime. The iterative process is repeated until convergence to a final number density now corrected for sheath expansion. The maximum value of $\mathrm{d} / \mathrm{r}$ is 9 occurring near the anode.

\section{B. Dual Primary and Maxwellian Electron Analysis}

Several atempts were made to analyze the centerline $\mathrm{FV}$ traces, on-axis with the discharge cathode orifice, assuming a dual primary and Maxwellian electron distribution. ${ }^{30,31}$ Off-centerline I-V curves in the discharge cathode plume revealed extensive noise that precluded the more detailed dual population analysis. Outside of the discharge cathode plume, it is unlikely that a significant number of primary electrons can be detected to obtain accurate results using the dual population analysis. The main benefit of the dual analysis is offering additional information about the primary electron energy and primary electron number density. 
The dual population analysis, assumes that the electrons in the discharge chamber consist of monoenergetic primary and Maxwellian electrons. This is not an unreasonable assumption based upon the interaction between the discharge cathode, the discharge plasma, and the magnetic field. Physically, the monoenergetic primary electrons are those electrons emitted from the cathode that are accelerated over the full discharge voltage drop and have not undergone a collision yet. Though these primary electrons will have some spread, for simplicity they are assumed to be monoenergetic.

The Maxwellian or thermalized electrons are those electrons that have undergone enough collisions to have a distribution of energies. Experimental results verify that the dual population is in fact a good assumption. ${ }^{30,31}$ Several attempts were made to fit each FV characteristic with the theoretical current curve expected for such a dualpopulation distribution. The assumed current form consists of a linear monoenergetic primary electron component and an exponential Maxwellian component shown in Equation $6 .^{31}$

$$
I=B_{1}+B_{2} V_{b i a s}+B_{3} \exp ^{\left(B_{4} V_{b i a s}\right)}
$$

The graphing package Igor was used to fit to the current-voltage traces incorporating the nonlinear LevenbergMarquardt fit method yielding the Maxwellian and primary plasma parameters. Difficulty fitting the current-voltage characteristic resulted in nonrealistic fit coefficients such as negative electron temperatures or negative contributions to the current by the primary electrons.

A second attempt was made to analyze the I-V data on centerline using a piecemeal approach. The ion saturation current is first subtracted from the probe collected current leaving only the electron component to the IV characteristic. The primary component of the characteristic is determined by a fit to the linear region near the floating potential of the resulting electron current as a function of voltage. The primary electron energy is found by subtracting the voltage at which the primary electron current is zero from the plasma potential illustrated by Equation 7. ${ }^{31}$ Although the plasma potential could not be determined from the Langmuir probe data due to a lack of electron saturation, the plasma potentials on centerline are available from emissive probe measurements in the FMT2. ${ }^{33}$

$$
\zeta_{p}=\phi_{p}+\frac{B_{1}}{B_{2}}
$$

The primary electron number densities can be calculated according to:

$$
n_{p}=\left[\frac{8 m_{e}}{q \zeta_{p}}\right]^{1 / 2} \frac{i_{p}}{A_{s} q}
$$

where $i_{p}$ is the primary electron current at plasma potential found by extrapolating the linear primary fit to the plasma potential value measured by the emissive probe. The primary electron current is then subtracted from the electron current characteristic resulting in the Maxwellian current. The electron temperature is calculated by plotting the semi$\log$ of the resulting Maxwellian current as a function of voltage. Linear fit to the electron repelling region yields the electron temperature. The ion number density and thus total electron number density are found, using the Bohm approximation $^{22-24}$ for ion velocity, given by Equation 3.

Implication of this analysis proved troublesome. Probe I-V characteristics often did not have a well defined linear region, thus the almost arbitrary selection of a range to fit the primary linear region resulted in a wide range of primary electron plasma parameters. Attempts to fit multiple voltage ranges yielded results with high sensitivity to the range selected. Inspection of the natural log of current with respect to voltage often became more nonlinear after primaries were subtracted. It is possible that more data pairs on the I-V curve, or multiple traces averaged, could lead to reliable primary electron information. The dual population results have been omitted due to difficulty in the applying the analysis to the data pairs resulting from this experiment. 
The partial I-V characteristics on centerline appear to be linear, possibly indicating that all of the electrons near the DCA on-axis are primaries. This could explain the difficulty fitting the dual primary and Maxwellian current to the existing centerline data. The closest axial location at TOC 8a operation, on DCA centerline, was analyzed assuming all primary electrons using a plasma potential of 15 volts (relative to cathode common) from emissive probe results at that location. ${ }^{33}$ The analysis yields primary electrons with an energy of $9 \mathrm{eV}$ (on the order of the ionization potential of xenon) and a number density of $7 \times 10^{12} \mathrm{~cm}^{-3}$. Calculating the "orifice" area size that these primaries would need in order to carry the $8.24 \mathrm{~A}$ of discharge current gives a diameter on the order of the cathode keeper diameter, which is not unreasonable considering the interrogation is done $1.5 \mathrm{~mm}$ downstream of the keeper. Electron energy distribution function measurement will allow clarification of the ratio of primary to total electron number density.

\section{Results and Discussion}

All discharge plasma locations have been normalized based upon the discharge cathode keeper diameter. The data are comparable to emissive and double Langmuir probe results in the FMT2 discharge chamber. The data are also easily compared to data taken by other researchers in near-DCA discharge chamber environments

\section{A. Maxwellian Electron Temperature Contours}

Below are graphical representations of the measured Maxwellian electron temperatures for varying thruster operating conditions both with and without beam extraction. The sporadic regions of increased electron temperature near the anode are a result of the combination of noise in the I-V characteristics at these locations and the reduction of the number of points in the region from which electron temperature is calculated. These high temperature data points should be ignored. Several results are evident from inspection of Figure 7. There appears to be no effect on electron temperature of shorting the cathode keeper to the discharge cathode common at the TOC 8 level. $4-6$ volts may be enough (or $8-12$ volts for Xe III) to account for the increased erosion in the ELT of the DS1 flight spare without having to change the number density and electron temperature. The good comparison in the DCA plume between TOC 8a and TOC 8 contours supports the repeatability of the measurement as they represent data taken with two different probe tips days apart.

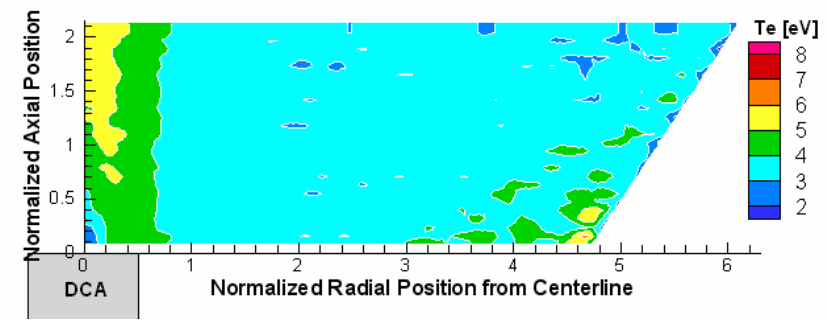

a)

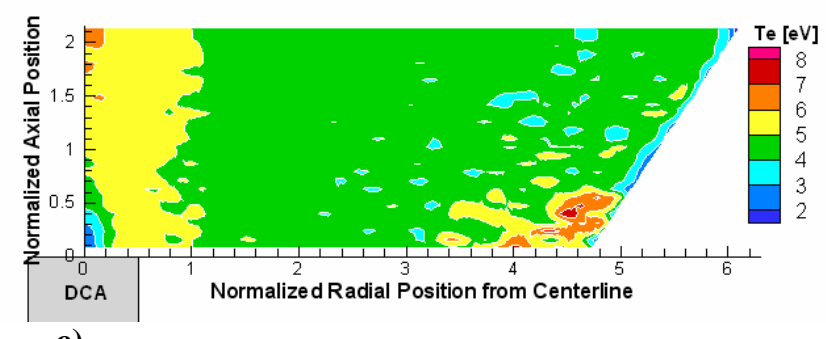

c)

Figure 7. Electron temperature mappings corresponding to similar operation to the NASA TH 8 throttling level. Thruster operating conditions are for $V_{d c}=25.10 \mathrm{~V}$ and $J_{d c}=8.24$ A where a) is DL 8 without beam extraction, b) is TOC 8a with beam on the first day of operation, c) is TOC 8 with beam for day two operation, and d) is TOC 8 with beam and the discharge keeper shorted to discharge cathode common. 
Throttling the engine up to higher power levels does not have a noticeable effect on the electron temperature profiles evident by profiles in Figures 7 and 8. A broadening of the higher electron temperature off-axis region is evident when a beam is extracted for all throttling points. Oscillations in both the discharge voltage and current are recorded prior to data collection to ensure discharge cathode operation is in spot mode, indicative of low oscillations (peak-to-peak voltage oscillations less than 5 volts). There is typically a slight increase in the discharge voltage oscillations when a beam is extracted, but this effect is unlikely the cause of the spread in electron temperature. Over all operating conditions, the maximum discharge voltage oscillations ranges from \pm 0.7 to \pm 1.4 volts peak-to-peak. Examples of the increase in discharge voltage oscillations with beam extraction range from the slight increase from \pm 0.75 to \pm 1.0 volts when transitioning from DL 8 to TOC 8 a to the largest increase from \pm 0.75 to \pm 1.33 volts when transitioning from DL 12 to TOC 12 . The suspicion that an increase in discharge voltage oscillations is causing the electron temperature broadening is further reduced by comparing contours DL 8 , TOC 8 , and TOC keeper shorted to common, which all have discharge voltage oscillations of \pm 0.75 volts though a significant spread in the electron temperature plume is evident between DL 8 and the other two conditions with beam extraction.

It is not immediately clear why there would be a slight dip in electron temperature on the discharge cathode centerline close to the DCA. It is possible that alignment shifts during pump downs are occurring, but this effect would have to be as repeatable as the data taken for three different pump downs.

Similar electron temperature profiles were produced with the double Langmuir probe in FMT2 offering agreement in the magnitude of electron temperatures measured and also in the broadening of electron temperature with extraction of a beam. ${ }^{18}$ Data taken then indicate electron temperatures from $2-7 \mathrm{eV}$ over similar operating conditions with a clearly defined discharge cathode plume. ${ }^{18}$

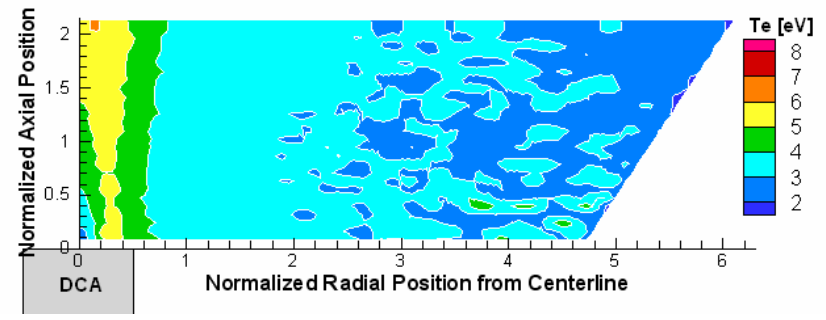

a)

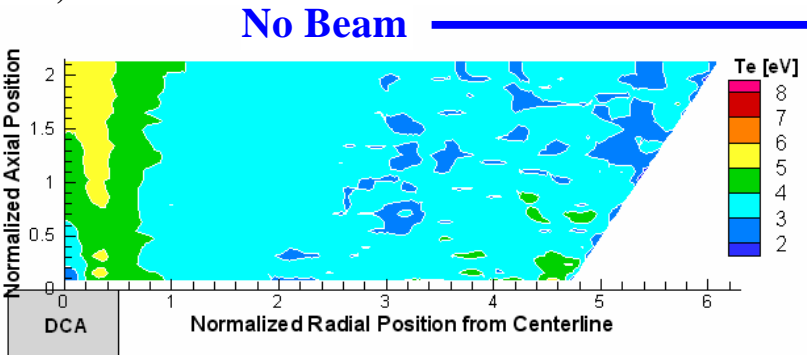

c) throttling levels. Thruster operating conditions are $\mathrm{V}_{\mathrm{dc}}=25.40 \mathrm{~V}, \mathrm{~J}_{\mathrm{dc}}=10.87 \mathrm{~A}$ for a) DL 12 without beam extraction and for b) TOC 12 with beam extraction. Thruster operating conditions are $V_{d c}=25.30 \mathrm{~V}, J_{\mathrm{dc}}=13.13 \mathrm{~A}$ for c) DL 15 without beam extraction and for d) TOC 15 with beam extraction.

\section{B. Ion/Electron Number Density Contours}

Ion/electron number density data are presented again for various throttled operating conditions both with and without beam extraction (Figs. 9 and 10). Shorting of the discharge keeper to the discharge cathode common does not have a noticeable effect on the measured number densities. The data illustrate the opposite trend of the electron temperature measurements in that the number density data taken with beam extraction tends to be more collimated compared to the same discharge conditions without beam extraction. 


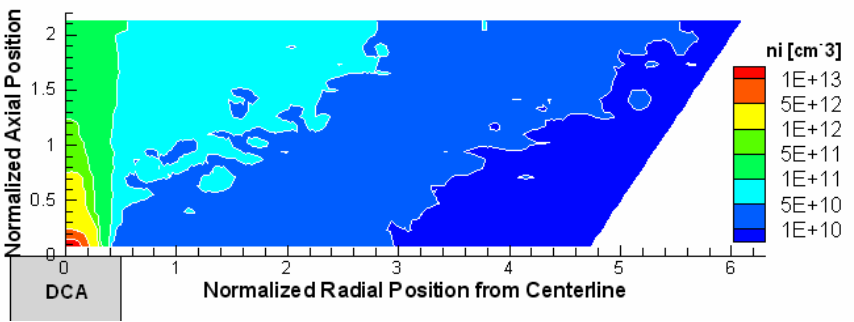

a)

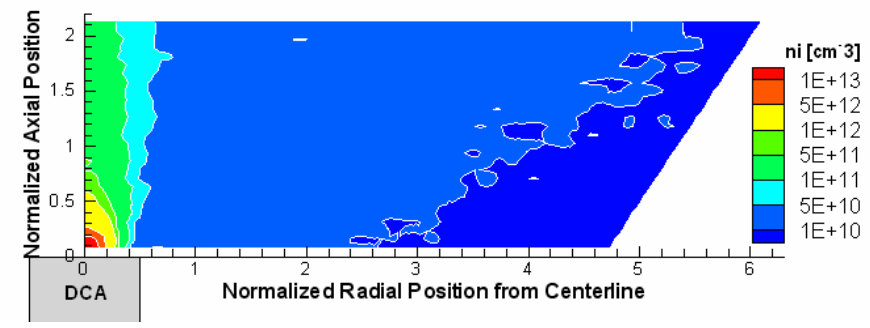

c)

Figure 9. Electron/Ion number density mappings corresponding to similar operation to the NASA TH8 throttling level. Thruster operating conditions are for $V_{d c}=25.10 \mathrm{~V}$ and $J_{d c}=8.24$ A where a) DL 8 is without beam extraction, b) TOC 8a is with beam on the first day of operation, c) TOC 8 is with beam on day two operation, and d) TOC 8 is with beam and the discharge keeper shorted to discharge cathode common.

Collimation of the plasma plume number density and a broadening of the electron temperature occur when a beam is extracted regardless of the fact that the mass flow rates of the thruster, with beam extraction, are much higher than those with discharge cathode operation only. Beam extraction, with comparable mass flow rates, would cause a decrease in the pressure inside the discharge chamber as ions (previously atoms) leave the chamber. Thus, there are fewer ionizing collisions with beam extraction resulting in a decrease in the ion number density. Fewer neutrals are available to cool the electrons (via inelastic collisions) resulting in a broadening of the high electron temperature plume. One expects that the substantially higher mass flow rates with beam extraction would dominate the aforementioned effect, resulting in an increase in ion number density and a narrowing of the high electron temperature plume yet the data do not support this expectation.

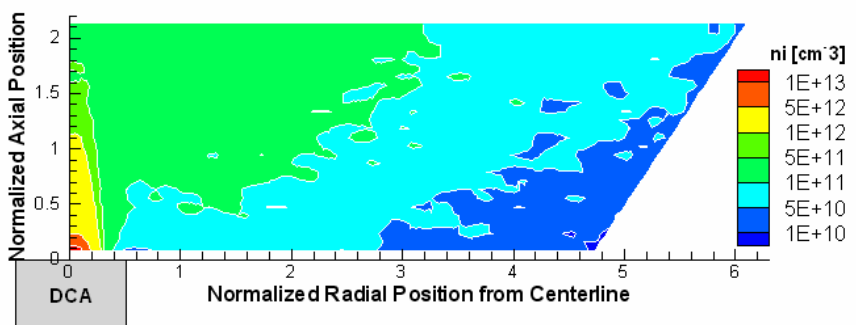

a)

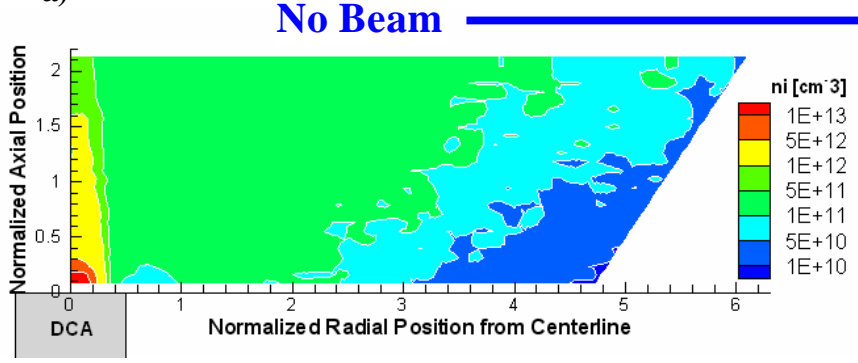

c)

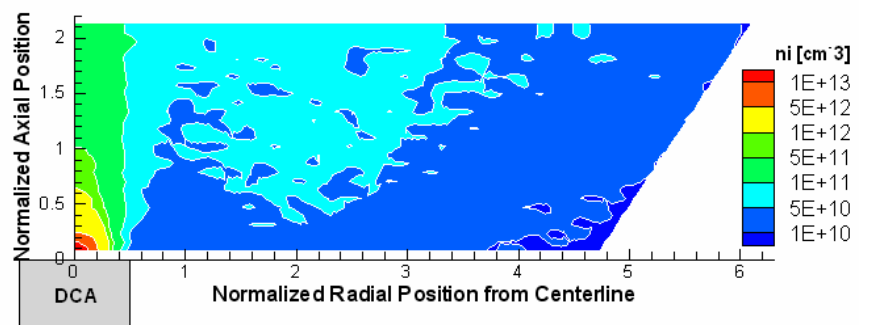

b) $\longrightarrow$ Beam Extraction

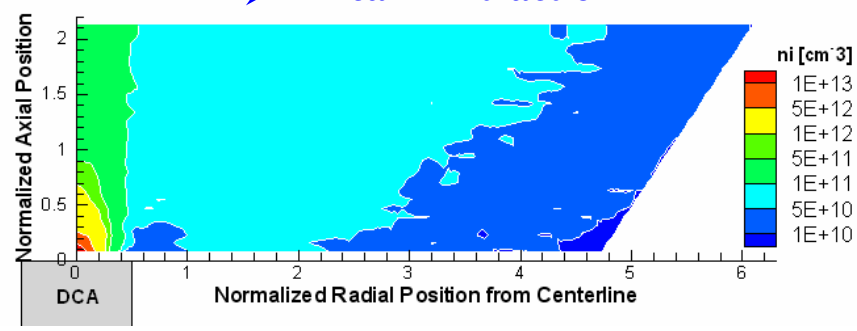

d)

Figure 10. Electron/Ion number density mappings corresponding to similar operation to the NASA TH12 and TH15 throttling levels. Thruster operating conditions are $V_{d c}=25.40 \mathrm{~V}, J_{d c}=10.87$ A for a) DL 12 without beam extraction and for b) TOC 12 with beam extraction. Thruster operating conditions are $V_{d c}=25.30 \mathrm{~V}, J_{d c}=13.13 \mathrm{~A}$ for c) DL 15 without beam extraction and for d) TOC 15 with beam extraction. 
As predicted the single Langmuir probe measures slightly higher number densities than the previous measurements using the double Langmuir probe. The near DCA double probe number densities were as high as $3 \times 10^{12}$ per $\mathrm{cm}^{3}$. The single Langmuir probe number density is as high as $1 \times 10^{13}$ per $\mathrm{cm}^{3}$ directly at the cathode exit plane indicating that a significant pump down misalignment has not likely occurred. Outside of the plume comparable number densities ranging from $1 \times 10^{10}$ to $5 \times 10^{11}$ are measured using the double probe. ${ }^{18}$

\section{Plasma Potential and Debye Length}

Plasma potentials are estimated from the location of the "knee" in the I-V characteristics for spatial locations in which electron saturation is reached. Electron current saturation is not reached in the high-density cathode plume region due to the limitation of the Langmuir probe circuit. Analysis of the plasma potentials does not indicate any discernable trends, which is not surprising due to the uncertainty in estimating the characteristic "knee" location. The overall magnitude of the main discharge plasma region ranges from 28 to 31 volts and can be seen in Figure 11. Plasma potential profiles obtained from the single Langmuir probe are consistent with emissive probe results. ${ }^{33}$

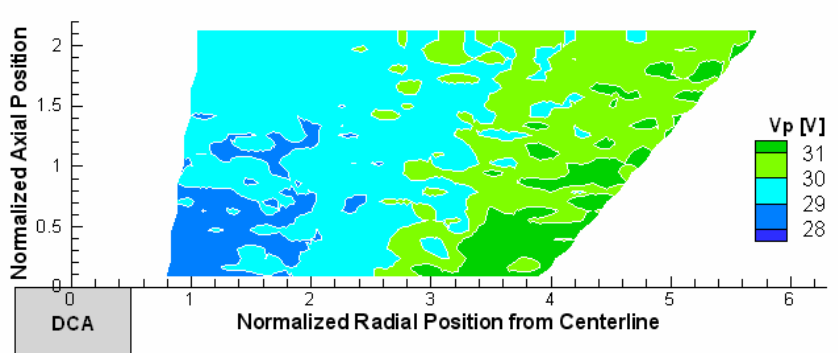

a)

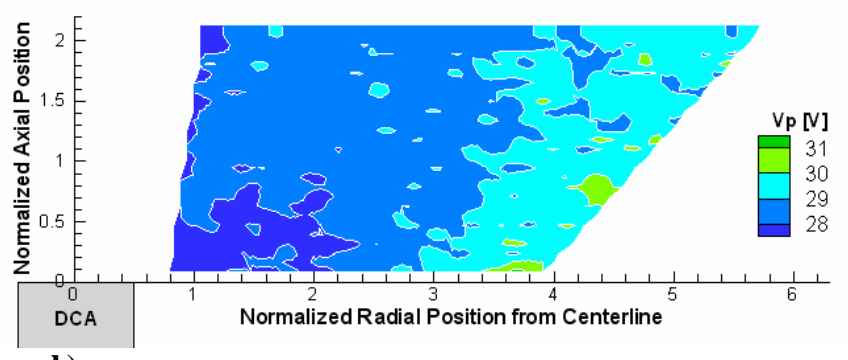

b)

Figure 11. Plasma potential data corresponding to TOC $8 V_{d c}=25.10$ a) and DL $15 V_{d c}=25.30$ b).

The analysis used for the single Langmuir probe data begins with the thin sheath assumption. Although any departure from the thin sheath regime is accounted for by the iterative sheath expansion analysis, it is of interest to calculate how well this assumption is satisfied. Figure 12 illustrates the worst and best cases for the size of the Debye length, a measure of the sheath size, for all the data analyzed. In the high-density discharge cathode plume region the Langmuir probe electrode $(0.18 \mathrm{~mm}$ in diameter) is much larger than the Debye length. As the number density drops off towards the anode, the Debye length quickly grows eventually exceeding the electrode radius. The thin sheath assumption is clearly satisfied for the near DCA region of interest. Although there is significant departure from thin sheath near the anode, the probe is not yet in the OML regime. The iterative sheath calculation, which accounts for the departure from thin sheath, should yields accurate results in this region as the sheath grows.

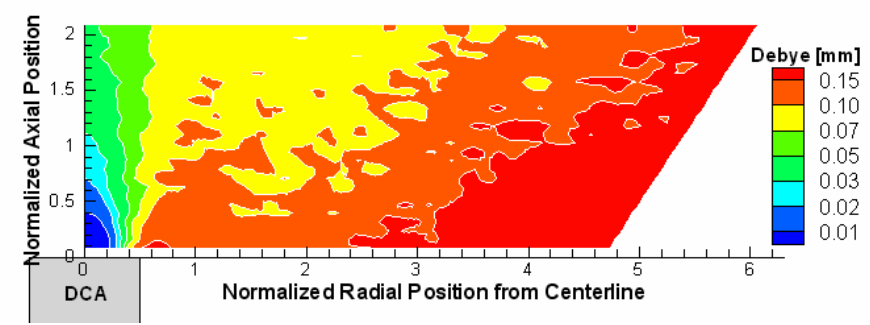

a)

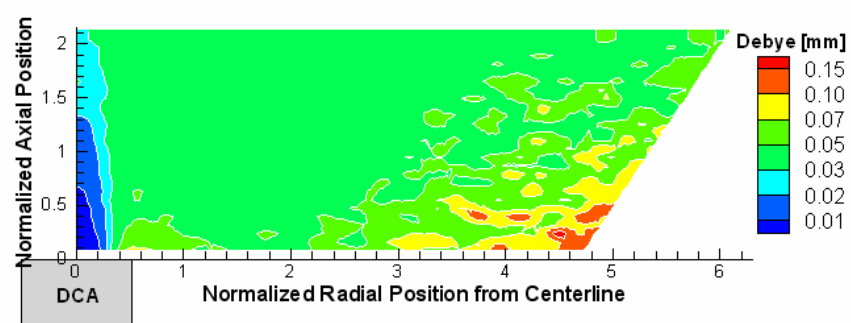

b)

Figure 12. Debye Lengths calculated corresponding to TOC 8 a) and DL 12 b).

\section{Error Analysis}

Traditional estimates of the error in electrostatic probe measurements are $50 \%$ for electron number density and $20 \%$ for electron temperature. ${ }^{26}$ While these errors are large, the relative error between two measurements using identical setups is not believed to be as large. Noise in measured electron temperatures is evident due to the combination of errors in estimating both the slope at the zero bias location and the ion saturation current. Comparison of the data taken at TOC 8 a and TOC 8 indicate the repeatability of the engine and electrostatic probe setup. The number density and electron temperature data, taken during different facility pump downs, illustrates comparable results from two different probe tips. 
Although the full dual population analysis by Beattie could not be implemented, estimation of the primary electron parameters was possible assuming all primary electrons immediately downstream of the DCA yielding reasonable values. The error in primary parameters has been calculated by Beattie to be $37 \%$ for primary electron energy, and $285 \%$ for primary electron density. ${ }^{31}$

\section{Conclusions}

Discharge plasma data are presented inside an NSTAR-type ion engine as a function of operating condition over a range of thruster throttling points both with and without beam extraction for comparison. The data are consistent with data taken in electron-bombardment ion engine discharge chambers made by other researchers including double probe measurements made in the FMT2 thruster discharge. The widening of the higher electron temperature region and collimation of the high-density number density region occurred for all throttled conditions when a beam was extracted and does not appear to result from increased discharge voltage oscillations. Throttling the engine to higher power levels does not alter the electron temperature profiles, but does result in an increase in the number density consistent with the higher flow rates and discharge current at these conditions. Shorting of the discharge keeper to the discharge cathode common does not have a noticeable affect on the discharge plasma structure. Plasma potential measurements agree, in magnitude, to emissive probe measurements taken in the thruster. Primary electron parameters were calculated assuming all primary electrons indicating a need to measure the electron energy distribution function of the near-DCA discharge plasma.

\section{Appendix}

Nominal Thruster Operating Conditions (TOC Levels) with beam extraction, Discharge Levels (DL Levels) without beam extraction, and reference NASA Throttling Levels (TH Levels).

\begin{tabular}{|c|c|c|c|c|c|c|c|c|c|c|c|c|c|}
\hline & & & & & & & & & & Main & $\begin{array}{c}\text { Disch. } \\
\text { Cath. } \\
\text { flow }\end{array}$ & $\begin{array}{c}\text { Neut. } \\
\text { Cath. } \\
\text { flow }\end{array}$ & $\begin{array}{c}\text { Corrected } \\
\text { Pressure }\end{array}$ \\
\cline { 2 - 15 } Level & $\mathrm{V}$ & $\mathrm{A}$ & $\mathrm{V}$ & $\mathrm{V}$ & $\mathrm{A}$ & $\mathrm{V}$ & $\mathrm{mA}$ & $\mathrm{V}$ & $\mathrm{A}$ & $\mathrm{sccm}$ & $\mathrm{sccm}$ & $\mathrm{sccm}$ & Torr \\
\hline \hline TH 8 & 25.10 & 8.24 & - & 1100 & 1.10 & -180.0 & 3.14 & 15.32 & 1.50 & 14.41 & 2.47 & 2.40 & - \\
\hline DL 8 & 25.12 & 8.24 & - & - & - & - & - & - & - & 15.7 & 3.85 & - & $1.9 \mathrm{E}-06$ \\
\hline TOC 8a & 25.12 & 8.24 & 6.70 & 1100 & 1.10 & -180.0 & 4.41 & 16.83 & 1.50 & 16.0 & 3.81 & 4.61 & $2.3 \mathrm{E}-06$ \\
\hline TOC 8 & 25.10 & 8.24 & 6.96 & 1100 & 1.10 & -180.0 & 4.47 & 18.06 & 1.50 & 15.5 & 4.87 & 4.86 & $2.3 \mathrm{E}-06$ \\
\hline TOC 8 CK- & & & & & & & & & & & & & \\
CC shorted & 25.10 & 8.24 & 0.00 & 1100 & 1.10 & -180.0 & 4.40 & 17.63 & 1.50 & 15.5 & 4.92 & 4.86 & $2.4 \mathrm{E}-06$ \\
\hline TH 12 & 25.40 & 10.87 & - & 1100 & 1.49 & -180.0 & 4.70 & 14.52 & 1.50 & 19.86 & 2.89 & 2.81 & - \\
\hline DL 12 & 25.45 & 10.87 & - & - & - & - & - & - & - & 15.7 & 2.94 & - & $1.8 \mathrm{E}-06$ \\
\hline TOC 12 & 25.40 & 10.87 & 6.34 & 1100 & 1.49 & -180.0 & 6.56 & 17.50 & 1.50 & 21.1 & 3.30 & 4.61 & $2.7 \mathrm{E}-06$ \\
\hline TH 15 & 25.14 & 13.13 & - & 1100 & 1.76 & -180.0 & 5.99 & 14.02 & 1.50 & 23.43 & 3.70 & 3.60 & - \\
\hline DL15 & 25.15 & 13.13 & - & - & - & - & - & - & - & 15.1 & 2.77 & - & $1.8 \mathrm{E}-06$ \\
\hline TOC 15 & 25.10 & 13.13 & 6.30 & 1100 & 1.76 & -180.0 & 8.37 & 16.13 & 1.50 & 24.5 & 3.06 & 4.61 & $2.9 \mathrm{E}-06$ \\
\hline
\end{tabular}

\section{Acknowledgements}

We would like to thank the entire research group at PEPL who have been instrumental in this investigation. We would also like to thank Mr. Michael Patterson of the NASA Glenn Research Center (GRC) for the financial support of this research through research grant NAG3-2216 and for use of government equipment. We would like to acknowledge Dr. John Foster (grant monitor) and Dr. George Williams who have been principal contacts at NASA GRC. Mr. Daniel Herman is supported through a Department of Defense NDSEG fellowship.

\section{References}

[1] Polk, J. E., et al., "An Overview of the Results from an 8200 Hour Wear Test of the NSTAR Ion Thruster," AIAA Paper \# 992446, $35^{\text {th }}$ AIAA / ASME / SAE / ASEE Joint Propulsion Conference, Los Angeles, CA, June 1999.

[2] Williams, G. J., et al., "Characterization of FMT-2 Discharge Cathode Plume," IEPC Paper \#99-104, 26 ${ }^{\text {th }}$ International Electric Propulsion Conference, Ketakiushu, Japan, Oct. 1999.

[3] Anderson, J. R., et al, "Performance Characteristics of the NSTAR Ion Thruster During and On-Going Long Duration Ground Test," IEEE Paper No. 8.0303, IEEE Aerospace Conference, Big Sky, MT, Mar. 2000.

[4] Domonkos, M. T., Foster, J. E., Patterson, M. J., "Investigation of Keeper Erosion in the NSTAR Ion Thruster," IEPC Paper No. 01-308, $27^{\text {th }}$ International Electric Propulsion Conference, Pasadena, CA, Oct. 2001. 
[5] Sengupta, A., Brophy, J. R., and Goodfellow, K. D., "Wear Characteristic from the Extended Life Test of the DS1 Flight Spare Ion Thruster," $28^{\text {th }}$ International Electric Propulsion Conference, Toulouse, France, March 17-21, 2003.

[6] Sengupta, A., Brophy, J. R., and Goodfellow, K. D., "Status of the Extended Life Test of the Deep Space 1 Flight Spare Ion Engine after 30,352 Hours of Operation," AIAA-2003-4558, 39 ${ }^{\text {th }}$ AIAA / ASME / SAE / ASEE Joint Propulsion Conference, Huntsville, AL, June 20-23, 2003.

[7] Olsen, S., and Katz, I., "Electric Propulsion for Project Prometheus," AIAA-2003-5279, 39 th AIAA / ASME / SAE / ASEE Joint Propulsion Conference, Huntsville, AL, June 20-23, 2003.

[8] Patterson, M.J., Foster, J.E., Haag, T.W., Pinero, L., Soulas, G.C., "Ion Propulsion Development Activities at the NASA Glenn Research Center," AIAA-2003-4709, 39 $9^{\text {th }}$ AIAA / ASME / SAE / ASEE Joint Propulsion Conference, Huntsville, AL, June 20-23, 2003.

[9] Williams, G. J., The Use of Laser-Induced Fluorescence to Characterize Discharge Cathode Erosion in a $30 \mathrm{~cm}$ Ring-Cusp Ion Thruster, Ph.D. Dissertation, University of MI, 2000.

[10] Kameyama, I., and P. J. Wilbur, "Potential-Hill Model of High-Energy Ion Production Near High-Current Hollow Cathodes," ISTS-98-Aa2-17, $21^{\text {st }}$ International Symposium on Space Technology and Science, (May, 1998).

[11] Hayakawa, et al, "Measurements of Electron Energy Distributions in a $14 \mathrm{~cm}$ Diameter Ring Cusp Ion Thruster," Journal of Propulsion and Power, Vol. 8, pp. 118-126, Jan-Feb, 1992.

[12] Herman, D. A., McFarlane, D. S., and Gallimore, A. D., "Discharge Plasma Parameters of a 30-cm Ion Thruster Measured without Beam Extraction using a High-Speed Probe Positioning System," IEPC-03-0069, $28^{\text {th }}$ International Electric Propulsion Conference, Toulouse, France, March 17-21, 2003.

[13] Walker, M. L. R., Gallimore, A. D., "Pressure Map of a Facility as a Function of Flow Rate to Study Facility Effects," AIAA2002-3815, 38 th Joint Propulsion Conference, Indianapolis, Indiana, July 7-10, 2002.

[14] Hofer, R. R., Peterson, P. Y., Gallimore, A. D., "Characterizing Vacuum Facility Backpressure Effects on the Performance of a Hall Thruster,” IEPC Paper No. 01-045, $27^{\text {th }}$ International Electric Propulsion Conference, Pasadena, CA, Oct. 2001.

[15] Dushman, S., Scientific Foundations of Vacuum Technique, Vol. 4, Wiley, N.Y., 1958.

[16] Haas, J. W., et al, "Development of a High-Speed, Reciprocating Electrostatic Probe System for Hall Thruster Interrogation," Review of Scientific Instruments. Vol. 71, No. 11, pp. 4131-4138, Nov. 2000.

[17] Haas, J. W., Low-Perturbation Interrogation of the Internal and Near-Field Plasma Structure of a Hall Thruster using a HighSpeed Probe Positioning System, Ph.D. Dissertation, University of Michigan, 2001.

[18] Herman, D.A., and Gallimore, A.D., "Comparison of Discharge Plasma Parameters in a 30-cm NSTAR Type Ion Engine with and without Beam Extraction," AIAA-2003-5162, 39 ${ }^{\text {th }}$ AIAA / ASME / SAE / ASEE Joint Propulsion Conference, Huntsville, AL, June 20-23, 2003.

[19] Beattie, J. R., and Matossian, J. N., Mercury Ion Thruster Technology Final Report, NASA CR-174974, Hughes Research Labs. Feb. 1983 - Oct. 1984.

[20] Domonkos, M. T., Evaluation of Low-Current Orificed Hollow Cathode, Ph.D. Dissertation, University of Michigan, 1999.

[21] Foster, J. E., and Patterson, M. J., "Plasma Emission Characteristics from a High Current Hollow Cathode in an Ion Thruster Discharge Chamber," AIAA-2002-4102, $38^{\text {th }}$ Joint Propulsion Conference, Indianapolis, Indiana, July 7-10, 2002.

[22] Chen, F.F. Introduction to Plasma Physics and Controlled Fusion: Vol. 1 Plasma Physics, Plenum Press, New York, N.Y., 1984.

[23] Chen, F. F., Plasma Diagnostic Techniques: Ch. 4 Electric Probes, Academic Press, New York, N.Y., 1965.

[24] Mott-Smith, H., and Langmuir, I. Physics Review, Vol. 28, 727, 1926.

[25] Hershkowitz, N., "How Langmuir Probes Work," Plasma Diagnostics. Nuclear Engineering and Engineering Physics Department, Univ. of Wisconsin-Madison, 1989.

[26] Hutchinson, I. H., Principles of Plasma Diagnostics, Cambridge University Press, New York, N.Y., 1987.

[27] Schott, L. Plasma Diagnostics: Ch. 11 Electrical Probes, American Elsevier Publishing Co, New York, N.Y., 1968.

[28] Passoth, E., et al, "An experimental study of plasma density determination by a cylindrical Langmuir probe at different pressures and magnetic fields in a cylindrical magnetron discharge in heavy rare gases," Journal of Physics D., Vol. 30, No. 12, June 1997, p. $1763-77$.

[29] Aikawa, H., "The Measurement of the Anisotropy of Electron Distribution Function of a Magnetized Plasma," Journal of the Physical Society of Japan, Vol. 40, No. 6, June 1976.

[30] Strickfaden, W.B., and Geiler, K.L., "Probe Measurements of the Discharge in an Operating Electron Bombardment Engine," AIAA Journal, Vol. 1, No. 8, August 1963, pp. 1815 - 1823.

[31] Beattie, J.R., "Numerical Procedure for Analyzing Langmuir Probe Data," AIAA Journal, Vol. 3, No. 7, July 1975, pp. 950 - 952.

[32] Ruzic, D. D., Electric Probes for Low Temperature Plasmas, American Vacuum Society Educational Committee, New York, N.Y., 1994.

[33] Herman, D.A., and Gallimore, A.D., "Near Discharge Cathode Assembly Plasma Potential Measurements in a $30 \mathrm{~cm}$ NSTAR-type Ion Engine amidst Beam Extraction," AIAA-2004-3958, 40 th AIAA / ASME / SAE / ASEE Joint Propulsion Conference, Fort Lauderdale, FL, 11 - 14 July, 2004.

[34] NRL Plasma Formulary, NRL/PU/6790--00-426, Naval Research Laboratory, Washington, D.C., 2000.

[35] Williams, G. J., et al., "Near-Field Investigation of Ions Emitted from a Hollow Cathode Assembly Operating at Low-Power," AIAA-98-3658, 34 $4^{\text {th }}$ Joint Propulsion conference, July, 1998. 